\title{
Pengaruh Empathy dan Responsiveness Terhadap Minat Kunjungan Ulang Pelanggan
}

\author{
Rismawati Hamid ${ }^{1}$, Djoko Lesmana Radji ${ }^{2}$, Yulinda L. Ismail ${ }^{3}$ \\ ${ }^{1}$ Mahasiswa Jurusan Manajemen, Universitas Negeri Gorontalo \\ 2,3Dosen Jurusan Manajemen, Universitas Negeri Gorontalo \\ mimahamid123@gmail.com
}

\begin{abstract}
This research aims to find out (1) the effect of empathy towards the interest in revisiting Red Black Restaurant Gorontalo, (2) the effect of responsiveness towards the interest in re-visiting Red Black Restaurant Gorontslo, (3) the effect of empathy and responsiveness towards the interest in re-visiting Red Black Restaurant Gorontalo, both partially and simultaneously. The data analysis applies multiple regression analysis (more than 1 independent variable). The findings reveal that partially (1) empathy does not significantly influence towards the interest in revisiting, (2) responsiveness significantly influences towards the interest in revisiting. Simultaneously, independent variable (empathy and responsiveness) significantly influence towards dependent variable (interest in re-visiting Red Black Restaurant Gorontalo). The $\mathrm{R}$ square value is 0,576 . This value shows thas as much as $57,6 \%$ variable of interest in re-visiting Red Black Restaurant Gorontalo can be explained by empathy and responsiveness, while the rest $42,4 \%$ can be explained by other variables excluding from this research.
\end{abstract}

Keywords: Empathy, Responsiveness, Interest in Re-visiting

\section{Pendahuluan}

Salah satu bisnis kuliner yang banyak diminati pelaku bisnis di Indonesia yaitu Restoran/rumah makan, karena bisnis yang bergerak di bidang kuliner ini termasuk bisnis dengan profit yang besar dan juga banyak diminati oleh masyarakat, dikarenakan setiap manusia pasti membutuhkan makanan. Akan tetapi banyak juga para pelaku usaha kuliner yang bangkrut, karena strategi pemasaran yang digunakan kurang tepat dan kualitas pelayanan yang kurang optimal. Sama halnya dengan keberhasilan sebuah bisnis kuliner dalam memenangkan persaingan ditentukan oleh penerapan srategi pemasaran yang tepat. Oleh karena itu penerapan strategi dalam bisnis kuliner sangat penting untuk memenangkan persaingan, salah satunya untuk meningkatkan minat berkunjung ulang ke restoran/rumah makan.

Restoran/rumah makan adalah suatu tempat atau bangunan yang diorganisir secara komersial yang memberikan sebuah pelayanan yang baik kepada tamunya yang datang, 
baik berupa makanan dan minuman. Makanan dikategorikan sebagai kebutuhan primer seseorang, tidak heran apabila makanan merupakan faktor penting agar manusia dapat terus bertahan hidup. Setiap individu memiliki kebutuhannya sendirisendiri dan cara pemuasan kebutuhan yang berbeda antara satu dengan yang lainnya. Kebanyakan orang dalam memilih pemuas kebutuhannya lebih suka dilakukan dengan dilayani dan tidak perlu harus repot-repot. Orang tersebut biasanya akan lebih memilih pergi ke sebuah restoran/rumah makan untuk memuaskan kebutuhannya.

Minat kunjungan ulang ke restoran/rumah makan diberbagai penjuru di Indonesia terus bertambah. Hal tersebut disebabkan banyak orang dengan pendapatan tinggi yang memiliki waktu senggang dalam bekerja atau sekedar berbisnis memanfaatkan restoran/rumah makan sebagai tempat untuk menikmati dan meluangkan waktu untuk beristirahat karena merek mendapatkan apa yang mereka butuhkan dan disediakan oleh restoran/rumah makan tersebut. Umar (2003) mengemukakan minat berkunjung ulang merupakan perilaku yang muncul sebagai respon terhadap objek yang menunjukkan keinginan pelanggan untuk melakukan kunjungan ulang.

Dalam sebuah bisnis kuliner, minat kunjungan ulang akan tercipta apabila karyawan mampu memberikan empati (empathy) terhadap kebutuhan konsumen.
Selain itu, empati (empathy) juga merupakan sumber informasi yang efektif bagi manajemen dalam melakukan perbaikan terhadap pelayanannya. Parasuraman, Zeithaml dan Berry mengemukakan (dalam Suwaldiman dan Afuan Fajrian Putra, 2014) Empati berarti bahwa perusahaan memahami masalah para pelanggannya dan bertindak demi kepentingan pelanggan, serta memberikan perhatian personal dan memiliki jam operasi yang nyaman.

Selain memberikan empati (empathy) terhadap kebutuhan konsumen, karyawan juga harus mampu memberikan daya tanggap (responsiveness). Daya tanggap (responsiveness) merupakan salah satu faktor penting yang harus diperhatikan untuk mendapatkan minat kunjungan ulang. Parasuraman (1998) mengemukakan bahwa daya tanggap merupakan kemampuan perusahaan yang dilakukan langsung oleh karyawan untuk memberikan pelayanan dengan cepat dan tanggap. Baik tidaknya dalam memberikan daya tanggap (responsiveness) tergantung pada kemampuan karyawan dalam memenuhi harapan konsumen secara konsisten.

Konsumen yang merasa puas secara tidak langsung akan menciptakan minat berkunjung ulang dan mendorong terjadinya rekomendasi dari mulut ke mulut, bahkan dapat memperbaiki citra perusahaan dimata konsumen. Seiring berjalannya waktu, minat akan tempat kuliner juga semakin 
besar dikarenakan sangat dibutuhkannya lingkungan yang menarik dan unik serta suasana yang tidak didapatkan jika makan di tempat lain. Maka dari itu saat ini pelaku bisnis bersaing membuka dan menciptakan restoran karena melihat peluang memperoleh keuntungan yang besar.

Dalam penelitian yang dilakukan oleh Januar Efendi Panjaitan (2016) dengan judul penelitian "Pengaruh Kualitas Pelayanan Terhadap Kepuasan Konsumen Indomaret Kota Bukit Purwakarta", hasil analisisnya menunjukkan bahwa kualitas pelayanan berpengaruh secara simultan terhadap kepuasan, dan secara parsial variabel responsive memiliki pengaruh terbesar terhadap kepuasan konsumen. Begitu juga dengan dengan minat kunjungan ulang, dalam penelitian yang dilakukan oleh Triana Helmawati, Siti Dyah Handayani (2015) dengan judul penelitian "Pengaruh Kualitas Layanan Terhadap Minat Kunjungan Ulang Yang Dimediasi Oleh Kepuasan Pasien Di Klinik Rumah Zakat Yogyakarta", hasil yang didapat menunjukkan bahwa dimensi kualitas layanan (tangible, reliability dan assurance) tidak berpengaruh terhadap kepuasan pasien, sedangkan yang berpengaruh terhadap kepuasan pasien adalah (responsiveness dan empathy). Variabel kepuasan pasien terbukti berpengaruh terhadap minat kunjungan ulang. Berdasarkan dua penelitian sebelumnya, peneliti tertarik untuk melakukan penelitian dengan menggabungkan ketiga variabel yaitu, empathy, responsiveness dan minat kunjungan ulang. Dengan variabel masalahnya yaitu minat kunjungan ulang. Peneliti akan melakukan penelitian di Resto Red Black Gorontalo.

Resto Red Black Gorontalo yang berlokasi di Jl. Sultan Botutihe, Kota Timur merupakan salah satu jenis resto yang menyediakan beberapa menu makanan dan minuman. Resto red black ini didirikan sejak tahun 2014. Pada saat itu restoran ini masih terlihat biasa saja, namun seiring berkembangnya zaman, restoran ini merubah konsep restoran dengan konsep restoran yang lebih modern. Dari sinilah kemudian bisnis restoran berkembang dalam berbagai konsep hingga saat ini. Ada restoran tradisional, restoran cepat saji, kafe, dan sebagainya.

Konsep restoran red black yang lebih modern ini selain terlihat lebih menarik, juga dapat memanjakan mata para konsumen yang mengunjungi restoran ini sembari menunggu pesanan. Menumenu yang disajikan pun mempunyai penampilan yang tidak kalah menarik. Restoran red black ini menyajikan berbagai macam menu seperti rice bowl, french fries dan makanan/minuman lain dengan cita rasa lokal.

Adapun rumusan masalah yaitu: 1). apakah empathy berpengaruh terhadap minat kunjungan ulang resto red black 
gorontalo?, 2) apakah responsiveness berpengaruh terhadap minat kunjungan ulang resto red black gorontalo?, 3) apakah empathy dan responsiveness berpengaruh terhadap minat kunjungan ulang resto red black gorontalo?

\section{Kajian Teori}

\section{Definisi Minat Kunjungan Ulang}

Berikut beberapa uraian mengenai definisi minat kunjungan ulang oleh beberapa ahli:

1. Umar (2003) mengemukakan "minat kunjungan ulang merupakan perilaku yang muncul sebagai respon terhadap objek yang menunjukkan keinginan pelanggan untuk melakukan pembelian ulang".

2. Baker dan Crompton (2000) berpendapat bahwa minat kunjungan ulang adalah niat yang dimiliki pengunjung untuk mengunjungi suatu tempat dalam kurun waktu tertentu dan kesediaan mereka untuk sering melakukan kunjungan kembali ke tempat tersebut.

3. Kozak (2001) mengungkapkan minat berkunjung ulang merupakan tindakan nyata dalam menanggapi perilaku tertentu yang pada umumnya mengacu pada keinginan pengunjung untuk mengunjungi suatu tempat tujuan atau tempat tujuan lain.

4. Tjiptono (2005:231) mengemukakan minat berkunjung kembali adalah perilaku yang muncul sebagai respon terhadap objek. Minat berkunjung kembali menunjukkan keinginan untuk melakukan kunjungan kembali untuk waktu yang akan datang.

Dari beberapa pendapat di atas dapat dideskripsikan bahwa minat kunjungan ulang adalah perilaku seseorang yang muncul sebagai respon terhadap objek yang menunjukkan keinginan seseorang untuk melakukan pembelian ulang.

Indikator Minat Kunjungan Ulang

Dimensi atau indikator dari minat kunjungan ulang menurut Umar (2003) terdiri atas:

1) Karyawan memberikan pelayanan yang baik.

2) Menyediakan tempat yang nyaman untuk pelanggan.

3) Menyediakan produk yang menarik.

Faktor-faktor Yang Mempengaruhi Minat Kunjungan Ulang

1) Kualitas pelayanan, yang dimana konsumen atau pengunjung menginginkan kualitas pelayanan yang baik pada saat berkunjung ke suatu tempat.

2) Citra, bagi sebuah perusahaan merupakan persepsi masyarakat terhadap perusahaan itu sendiri. Persepsi ini muncul didasarkan pada apa yang masyarakat pandang, yang masyarakat ketahui tentang perusahaan tersebut. Citra perusahaan juga akan berpengaruh pada citra produk yang kedepannya bisa mempengaruhi preferensi untuk melakukan pembelian. Oleh karena itu setiap perusahaan mempunyai citranya masing-masing. Pembentukan citra 
juga dipengaruhi oleh familiaritas dari produk dan perusahaan yang bersangkutan. Familiaritas ini didapatkan dari informasi yang beredar di masyarakat, yang bersumber dari pengalaman pribadi, orang lain, maupun media massa. Citra sangat mempengaruhi keputusan seseorang dalam mengambil keputusan, karena citra yang baik akan berdampak positif bagi perusahaan dan citra yang buruk akan berdampak negatif terhadap perusahaan.

3) Daya tarik, suatu perusahaan yang bergerak dalam bidang produksi pada dasarnya ingin produknya terlihat berbeda dengan produk sejenis yang sudah ada. Oleh karenanya perusahaan harus menggali terus apa yang membuat produk tersebut berbeda. Dengan perbedaan produk tersebut diharapkan dapat memunculkan daya tarik suatu produk.

4) Promosi, merupakan salah satu bauran pemasaran yang digunakan oleh perusahaan untuk mengadakan komunikasi dengan pasarnya. Promosi juga sering dikatakan sebagai proses berlanjut, karena dapat menimbulkan rangkaian kegiatan selanjutnya bagi perusahaan.

\section{Definisi Empathy}

Berikut beberapa uraian mengenai definisi empathy oleh beberapa ahli:

1. Phillip Kotler dan Kevin Lane Keller (2008:52), mengemukakan empati sebagai kondisi memperhatikan dan memberikan perhatian pribadi kepada pelanggan.

2. Carkhuff dalam Asri Budiningsih (2004: 47) mengartikan empati sebagai kemampuan untuk mengenal, mengerti dan merasakan perasaan orang lain dengan ungkapan verbal dan perilaku, dan mengkomunikasikan pemahaman tersebut kepada orang lain.

3. Rambat Lupiyoadi (2001:148) mengemukakan empathy yaitu memberikan perhatian yang tulus dan bersifat individual atau pribadi yang diberikan kepada para pelanggan dengan berupaya memahami keinginan konsumen.

4. Parasuraman, Zeithaml, dan Berry (1988) yang dikutip dari Fandy Tjiptono, Ph.D \& Gregorius Chandra (2016:137) mengartikan empati bahwa perusahaan memahami masalah para pelanggannya dan bertindak demi kepentingan pelanggan, serta memberikan perhatian personal kepada para pelanggan dan memiliki jam operasi yang nyaman.

Dari beberapa pendapat di atas dapat dideskripsikan bahwa empati memiliki makna memberikan perhatian kepada pelanggan, memahami masalah para pelanggan dan bertindak demi kepentingan pelanggan.

\section{Indikator Empathy}

Dimensi atau indikator dari minat kunjungan ulang menurut Parasuraman et. al., 1990) terdiri atas:

1) Perhatian personal karyawan. 
2) Kesungguhan karyawan dalam melayani pelanggan.

3) Kemauan karyawan untuk mendengar dan menangani keluhan pelanggan.

\section{Upaya Meningkatkan Empathy}

Dalam suatu perusahaan diperlukan adanya empati yang dimiliki oleh karyawan. Banyak cara yang dapat dilakukan untuk meningkatkan empati pada karyawan. Menurut Daniel Goleman (1997:67) ada beberapa cara untuk meningkatkan empati yaitu:

1. Understanding others yaitu cepat menangkap perasaan orang lain (Respect), mampu merasakan dan membaca perasaan orang lain.

2. Service orientation yaitu memberikan pelayanan yang dibutuhkan orang lain, artinya mampu memberikan tindakan terhadap permasalahan yang sedang terjadi.

3. Developing others yaitu memberikan masukan positif atau membangun, artinya dapat memberikan solusi.

4. Leveraging diversity yaitu mengambil manfaat dari perbedaan bukan konflik, mampu mengambil manfaat dari permasalahan yang terjadi.

\section{Definisi Responsiveness}

Berikut beberapa uraian mengenai definisi responsiveness oleh beberapa ahli:

1. (Zeithmal et. $\mathrm{Al}, 1990: 120)$ mengemukakan responsiveness (daya tanggap) yaitu respon atau kesigapan karyawan dalam membantu pelanggan dan memberikan pelayanan yang cepat dan tanggap, yang meliputi: kesigapan karyawan dalam melayani pelanggan, kecepatan karyawan dalam menangani transaksi, dan penaganan keluhan pelanggan atau pasien.

2. Parasuraman, Zeithaml, dan Berry (1988) yang dikutip dari Fandy Tjiptono, Ph.D \& Gregorius Chandra (2016:137) mengartikan daya tanggap (responsiveness), berkenaan dengan kesediaan dan kemampuan para karyawan untuk membantu para pelanggan dan merespon permintaan mereka, serta menginformasikan kapan jasa akan diberikan dan kemudian memberikan jasa secara cepat.

3. Phillip Kotler dan Kevin Lane Keller (2008:52) mengungkapkan daya tanggap yaitu kesediaan membantu pelanggan dan memberikan layanan tepat waktu.

4. (Rambat Lupiyoadi, 2001:148) mengartikan responsiveness (ketanggapan) yaitu suatu kemauan untuk membantu dan memberikan pelayanan yang cepat (responsif) dan tepat kepada pelanggan, dengan penyampaian informasi yang jelas. Membiarkan konsumen menunggu tanpa adanya suatu alasan yang jelas menyebabkan persepsi yang negatif dalam kualitas pelayanan.

Dari beberapa pendapat di atas dapat dideskripsikan bahwa responsiveness (daya tanggap) adalah kemampuan karyawan dalam 
memberikan pelayanan yang cepat dan tanggap.

\section{Indikator Responsiveness}

Indikator atau dimensi responsiveness menurut

(Parasuraman et al., 1990) yaitu:

1. Kecepatan karyawan dalam melayani pelanggan.

2. Ketanggapan karyawan dalam membantu kesulitan pelanggan.
3. Kesediaan

karyawan memberikan informasi.

4. Kesiapan karyawan dalam merespon permintaan pelanggan.

\section{Kerangka Berpikir}

Berikut adalah kerangka pikir penelitian ini sebagaimana ditunjukkan pada gambar dibawah ini:

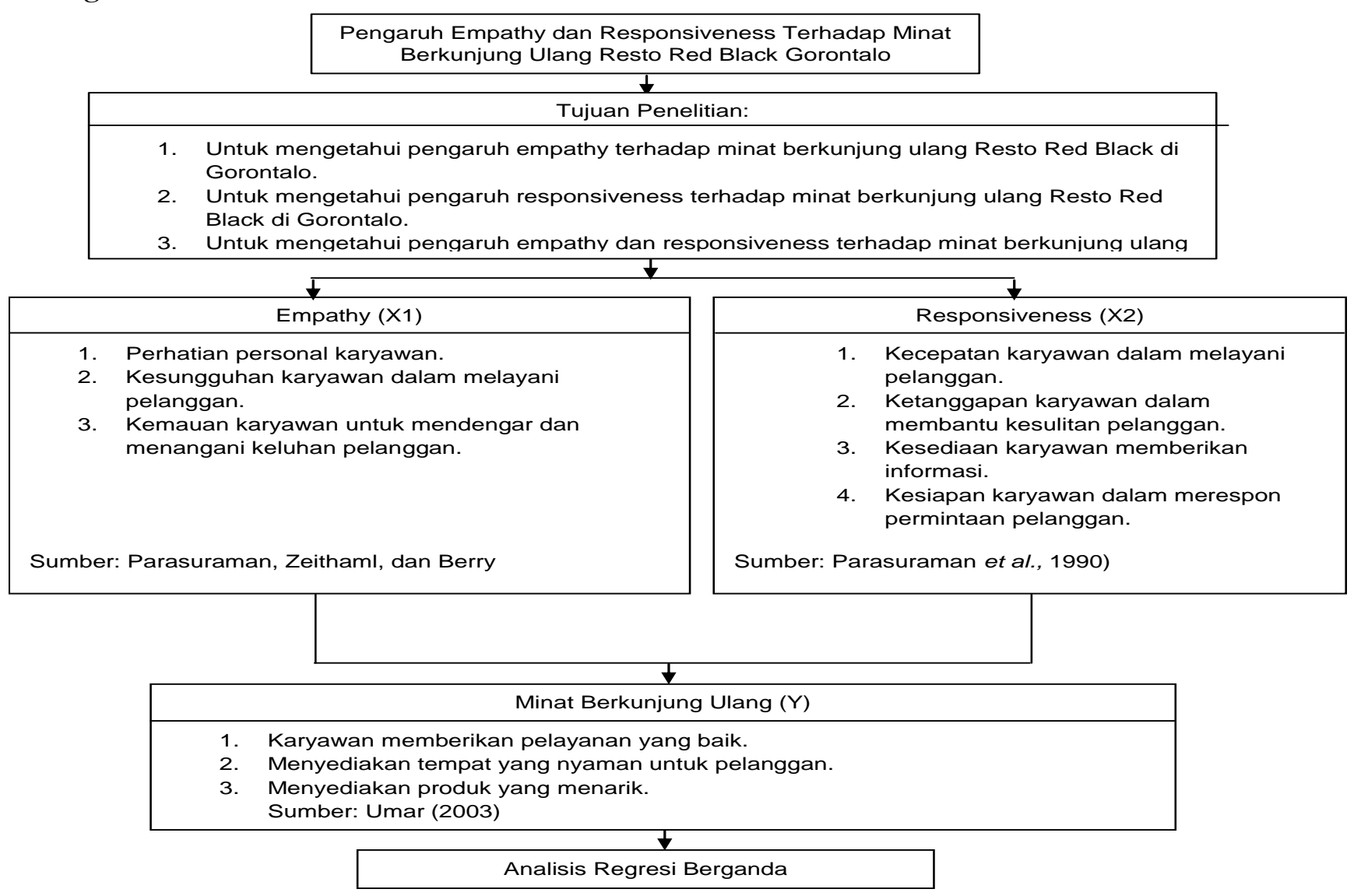

\section{Hipotesis}

Hipotesis dalam penelitian ini adalah sebagai berikut:

H1. Empathy berpengaruh terhadap Minat Kunjungan Ulang Resto Red Black Gorontalo.

H2. Responsiveness berpengaruh terhadap Minat Kunjungan Ulang Resto Red Black Gorontalo.
H3. Empathy dan Responsiveness berpengaruh terhadap Minat Kunjungan Ulang Resto Red Black Gorontalo.

\section{Metode Penelitian}

Tempat Penelitian

Tempat penelitian ini dilakukan di Resto Red Black Gorontalo, bertempat di Ruko Mall 
Gorontalo Blok A, Jl. Sultan Botutihe No. 68, Kota Timur, Kabupaten Bone Bolango, Gorontalo, 96115. Penetapan objek penelitian ini didasarkan atas pertimbangan sebagai berikut:

1. Objek yang diteliti dapat memberikan keterangan tentang masalah yang akan diteliti.

2. Data yang diperlukan cukup memadai.

\section{Waktu Penelitian}

Penelitian ini dilaksanakan dari bulan September 2019.

\section{Desain Penelitian}

Adapun desain penelitian untuk mengetahui hubungan dan pengaruh suatu variabel terhadap variabel lainnya sebagai berikut:

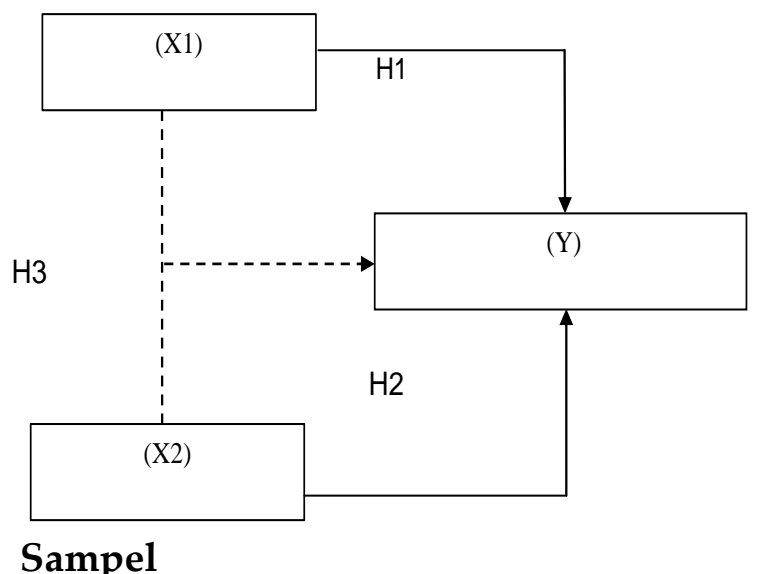

Menurut Sugiyono (2018: 149) sampel adalah bagian dari jumlah dan karakteristik yang dimiliki oleh populasi tersebut. Bila populasi besar, dan peneliti tidak mungkin mempelajari semua yang ada pada populasi. Untuk itu sampel yang harus diambil dari populasi betulbetul representative (mewakili), jadi sampel yang dapat diambil menggunakan Rumus Lameshow. Hal ini dikarenakan karena jumlah populasi tidak diketahui,Jumlah sampel dalam penelitian ini sebanyak 96 responden. Teknik pengambilan sampel dilakukan dengan teknik insidental seperti yang dikemukakan oleh Sugiyono (2014:85). Sampling Accidental adalah penentuan sampel berdasarkan kebetulan atau spontanitas artinya siapa saja yang secara tidak sengaja bertemu dengan peneliti, dan sesuai dengan karakteristik , maka orang tersebut dapat digunakan sebagai sampel.

\section{Pembahasan}

\section{Pengaruh Empathy Terhadap Minat Kunjungan Ulang Resto Red Black Gorontalo}

Empathy sangat penting untuk perusahaan-perusahaan, digunakan untuk memperhatikan dan memberikan perhatian terhadap orang lain serta dapat memberikan hubungan baik antara konsumen dengan karyawan Resto Red Black Gorontalo. Empathy yaitu memberikan perhatian yang tulus dan bersifat individual atau pribadi yang diberikan kepada para pelanggan dengan berupaya memahami keinginan konsumen (Rambat Lupiyoadi, 2001:148).

Hasil analisis deskriptif mengenai Empathy ditemukan bahwa rata-rata skor variabel Empathy yakni sebesar 5,577 atau dalam presentase yakni sebesar $77,45 \%$ yang berada pada kriteria cukup baik. Hal ini menunjukan bahwa konsumen cukup puas dengan empathy yang diberikan karyawan Resto Red Black Gorontalo. 
Hasil regresi bahwa Empathy tidak berpengaruh signifikan terhadap Minat Kunjungan Ulang Resto Red Black Gorontalo. Koefisien dari regresi untuk pengujian hipotesis pertama yakni negatif. Nilai $t$ negatif menunjukkan bahwa tidak adanya hubungan yang searah antara Empathy dengan Minat Kunjungan Ulang Resto Red Black Gorontalo.

\section{Pengaruh}

Responsiveness

Terhadap Minat Kunjungan Ulang Resto Red Black Gorontalo

Responsiveness atau daya tanggap secara umum diartikan sebagai keinginan untuk membantu, bagaimana memberikan layanan yang cepat dan menangani masalah atau komplain dengan baik. Atau dengan istilah lain yang sering kita dengar adalah tanggap terhadap kebutuhan konsumen. Sama halnya dengan konsumen pada umumnya, senang apabila karyawan Resto Red Black Gorontalo memperhatikan, melayani dengan cepat dan membantu pada saat mengalami masalah. Maka responsiveness yang dimaksudkan disini adalah pengukuran mengenai ketiga hal tersebut di atas.

Hasil analisis deskriptif mengenai Responsiveness ditemukan bahwa rata-rata skor variabel Responsiveness yakni sebesar 5,672 atau dalam presentase yakni sebesar $78,77 \%$ yang berada pada kriteria cukup baik. Hal ini menunjukan bahwa konsumen puas dengan Responsiveness yang diberikan karyawan Resto Red Black Gorontalo.
Berdasarkan hasil regresi bahwa Responsiveness berpengaruh signifikan terhadap Minat Kunjungan Ulang Resto Red Black Gorontalo. Koefisien dari regresi untuk pengujian hipotesis pertama yakni positif. Nilai $\mathrm{t}$ positif menunjukkan bahwa adanya hubungan yang searah antara Responsiveness dengan Minat Kunjungan Ulang Resto Red Black Gorontalo.

3. Pengaruh Empathy dan Responsiveness Terhadap Minat Kunjungan Ulang Resto Red Black Gorontalo

Minat kunjungan ulang merupakan perilaku yang muncul sebagai respon terhadap objek yang menunjukkan keinginan pelanggan untuk melakukan pembelian ulang. Maka dari itu karyawan Resto Red Black Gorontalo harus mampu memberikan pelayanan yang baik kepada pelanggan agar terciptanya keinginan pelanggan untuk melakukan kunjungan ulang.

Berdasarkan hasil gambaran umum responden dapat dijelaskan sebagai berikut:

a. Jumlah Responden Menurut Usia

Usia responden yang berkunjung di Resto Red Black Gorontalo sangat bervariasi. Mulai dari usia 19 tahun sampai dengan usia $>40$ tahun. Jumlah responden yang dominan adalah usia 21-30 tahun yaitu sebanyak 75 orang atau sekitar $78,1 \%$. Hal ini dikarenakan usia 21-30 tahun berada pada usia dewasa dan produktif yang memanfaatkan restoran/rumah makan sebagai tempat untuk 
menikmati dan meluangkan waktu untuk beristirahat karena mereka mendapatlan apa yang mereka butuhkan dan disediakan oleh restoran/rumah makan tersebut.

b. Jumlah Responden Menurut Jenis Kelamin

Responden yang berkunjung di Resto Red Black Gorontalo menurut jenis kelamin menunjukkan bahwa yang terbanyak ialah perempuan yakni sebanyak 59 orang atau sebesar $61,4 \%$. Hal ini dikarenakan perempuan paling suka pergi ke tempat-tempat yang menarik mata (instagramable) dibandingkan laki-laki.

c. Jumlah Responden Menurut Pekerjaan

Responden yang berkunjung di Resto Red Black Gorontalo menunjukkan bahwa yang paling dominan adalah pelajar atau mahasiswa/i yakni sebanyak 70 orang atau sekitar 72,9\%. Hal ini dikarenakan pelajar ataupun mahasiswa/i masih suka mencoba hal-hal baru seperti nongkrong dan bercengkrama bersama temantemannya di tempat yang menurut mereka asik.

Hasil jawaban responden atau analisis deskriptif ditemukan bahwa skor untuk variabel Minat Kunjungan Ulang Resto Red Black Gorontalo yakni sebesar 5,691 atau dalam presentase yakni sebesar 79,04\% yang berada pada kriteria cukup baik. Hal ini menunjukan bahwa adanya keinginan konsumen untuk melakukan kunjungan ulang di Resto Red Black Gorontalo.
Ditemukan pula bahwa besarnya koefisien korelasi yakni sebesar sebesar 0,752. Atau dengan kata lain, hubungan antar variabel bebas dengan variabel terikat yakni sebesar 75,2\%. Sehingga dapat dikatakan bahwa Variabel Empathy dan Responsiveness memiliki hubungan yang erat dengan variabel Minat Kunjungan Ulang Resto Red Black Gorontalo.

Kemudian untuk pengujian besar pengaruh (kemampuan variabel bebas dalam menjelaskan variabel terkait) menggunakan nilai $R$ Square, hasil R Square adalah sebesar 0,565 . Nilai ini menunjukkan bahwa sebesar 56,5\% variabel Minat Kunjungan Ulang Resto Red Black Gorontalo dapat dijelaskan oleh Empathy dan Responsiveness, sedangkan sisanya sebesar $43,5 \%$ dapat dijelaskan oleh variabel lain yang tidak diteliti dalam penelitian ini.

Pengaruh sebesar $\quad 43,5 \%$ tersebut merupakan pengaruh yang kuat sebagaimana dikutip dari kriteria dalam Ghozali (2005). Pengaruh yang kuat ini menunjukkan bahwa betapa penting Empathy dan Responsiveness terhadap Minat Kunjungan Ulang.

\section{Penutup \\ Simpulan}

Berdasarkan hasil penelitian dan pembahasan, maka dapat ditarik simpulan bahwa empathy dan responsiveness terletak pada kategori cukup baik. Untuk itu perlu ditingkatkan lagi agar empathy dan 
responsiveness karyawan bisa lebih baik lagi dan dapat menghasilkan pelayanan yang baik. Berdasarkan hasil pengujian hipotesis Empathy tidak berpengaruh signifikan terhadap Minat Kunjungan Ulang Resto Red Black Gorontalo. Nilai $\mathrm{t}$ negatif menunjukkan bahwa tidak adanya hubungan searah antara Empathy dengan Minat Kunjungan Ulang Resto Red Black Gorontalo. Responsiveness berpengaruh signifikan terhadap Minat Kunjungan Ulang Resto Red Black Gorontalo. Nilai $\mathrm{t}$ positif menunjukkan bahwa adanya hubungan yang searah antara Responsiveness dengan Minat Kunjungan Ulang Resto Red Black Gorontalo. Dan secara simultan variabel bebas (Empathy dan Responsiveness) secara bersamasama berpengaruh signifikan terhadap variabel terikat (Minat Kunjungan Ulang).

Saran

Berdasarkan simpulan yang telah diuraikan diatas, maka peneliti memberikan saran sebagai berikut:

1. Sebaiknya pimpinan Resto Red Black Gorontalo berupaya untuk memberikan arahan kepada karyawan agar lebih memberikan atau meningkatkan Empathy dan Responsiveness kepada konsumen.

2. Sebaiknya karyawan pada Resto Red Black Gorontalo berusaha meningkatkan kinerjanya melalui pemberian Empathy dan Responsiveness kepada konsumen.

3. Bagi peneliti selanjutnya sebaiknya merekonstruksi bentuk-bentuk pernyataan dalam penelitian ini, serta mengembangkan operasional variable. Langkah yang dapat dilakukan yakni dengan menggunakan skala guttman dalam pengumpulan data agar hasil jawaban responden dapat lebih objektif.

\section{Daftar Pustaka}

Baker, Dwayne A. dan John L. Crompton. 2000. "Quality, Satisfaction, and Behavioural Intentions" dalam Annals of Tourism Research, Vol 27, No 23. Great Britain: Elsevier.

Budiningsih, Asri. 2004. Belajar dan Pembelajaran. Yogyakarta: Rineka Cipta.

Hanggraningrum, Maya Dewi, Tita Hariyanti, Achmad Rudijanto. 2017. The Effect of Service Quality on Outpatient Satisfaction of Dr. Soegiri General Hospital Lamongan. Journal of Applied Management (JAM). Vol. 15, No.4.

Japarianto, Edwin. 2019. Pengaruh Retail Service Quality Terhadap Minat Berkunjung Ulang Mall Di Surabaya Melalui Perceived Quality dan Customer Satisfaction Sebagai Variabel Intervening. Jurnal Manajemen Pemasaran. Vol. 13 No. 1, Hal 17-26.

Juliana. 2019. Analisis Pengaruh Brand Image, Service Quality dan Price Terhadap Customer Satisfaction. Jurnal Manajemen. Vol. 8 No. 9, Hal 5867-5886.

Kotler, Phillip, Kevin Lane Keller. 2008. Manajemen Pemasaran. : Erlangga. 
Lupiyoadi, Rambat. 2001. Manajemen Pemasaran Jasa. Jakarta: Salemba Empat.

Maftuhah , Ida, Tanisah. 2015. The Effects of Service Quality, Customer Satisfaction, Trust and Perceived Value Towards Customer Loyalty. Jurnal Dinamika Manajemen. Vol. 6 No. 1, Hal 55-61.

Parasuraman, A., Zeithaml, V.A.and Berry, L.L. (1998), SERVQUAL: $a$ multiple item scale for Measuring consumer perceptions of service quality, Journal of Retaling, Vol. 64 No, 1, pp. 12-40.

Rahayu, Maria Putri. Pengaruh Customer Experience Terhadap Minat Berkunjung Ulang (Studi pada Pengunjung Museum Affandi Yogyakarta). Skripsi. Fakultas Ekonomi Universitas Sanata Dharma, Yogyakarta.

Raswendo. Pengaruh Kualitas Pelayanan Terhadap Minat Pembelian Ulang Pada Rumah Makan Puti Minang Raja Basa Bandar Lampung Dalam Perspektif Ekonomi Islam. Skripsi. Fakultas Ekonomi dan Bisnis Islam Universitas Islam Negeri, Raden Intan Lampung.

Rusdin. 2017. Pengaruh Kualitas Pelayanan Terhadap Tingkat Kepuasan Pemustaka di UPT Perpustakaan Universitas Tadulako. Jurnal Katalogis. Vol 5 No.1, Hal 65-77.

Sarwono, 2007 Analisis Jalur untuk Riset Bisnis dengan SPSS, Yogyakarta : Andi Offset

Schiffman, Leon G., Kanuk, Leslie Lazar. 2007. Perilaku Konsumen.
Alih Bahasa: Zoelkifli Kasip. Jakarta: Indeks

Schiffman, Leon G., Kanuk, Leslie Lazar. 2008. Perilaku Konsumen. Edisi Ketujuh. Alih Bahasa: Zoelkifli Kasip. Jakarta: Indeks.

Shadily, Hassan. Pemimpin Redaksi. 1987. Ensiklopedi Indonesia. Jilid 4. Jakarta: P.T. Ichtiar Baru - Van Hoeye.

Sugiyono. 2013. Metode Penelitian Manajemen. Bandung: ALFABETA.

Suwaldiman, Afuan Fajrian Putra. 2014. Pengaruh Kualitas Jasa Terhadap Tingkat Kepuasan Mahasiswa Akuntansi Dalam Mengikuti Pendidikan Profesi Akuntansi (Ppak). Jurnal Aplikasi Bisnis. Vol. 15, No.9.

Tandhia, Merry. 2016. Peningkatan Reliabilitas , Daya Tanggap dan Jaminan Pada Kualitas Layanan Starindo Healthy Group. Jurnal Manajemen dan Start-Up Bisnis. Vol 1 No. 1, Hal 1-8.

Tjiptono, Fandy. 2002. Manajemen Jasa. Yogyakarta: Andi.

Tjiptono, Fandy, Anastasia Diana. 2002. Total Quality Manajemen Edisi Revisi. Yogyakarta. Andy Offset.

Tjiptono, Fandy, Ph. D. \& Gregorius Chandra. 2016. Service, Quality dan Satisfaction. Yogyakarta: C.V ANDI. 